\title{
Far Lateral Disc Prolapse: Surgical Options in Limited Resources Centers
}

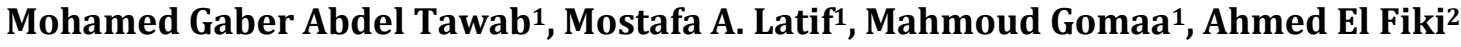 \\ ${ }^{1}$ Department of Neurosurgery, Fayoum University, Faiyum, Egypt \\ ${ }^{2}$ Department of Neurosurgery, Cairo University, Cairo, Egypt \\ Email: gaber_28@yahoo.com
}

How to cite this paper: Tawab, M.G.A., Latif, M.A., Gomaa, M. and El Fiki, A. (2019) Far Lateral Disc Prolapse: Surgical Options in Limited Resources Centers. Open Journal of Modern Neurosurgery, 9 , 199-207.

https://doi.org/10.4236/ojmn.2019.93019

Received: March 15, 2019

Accepted: May 5, 2019

Published: May 8, 2019

Copyright $\odot 2019$ by author(s) and Scientific Research Publishing Inc. This work is licensed under the Creative Commons Attribution International License (CC BY 4.0).

http://creativecommons.org/licenses/by/4.0/

\begin{abstract}
Far lateral disc prolapse accounts for $6.5 \%$ to $12 \%$ of all lumbar disc prolapses. Surgical options include open laminectomy with discectomy, microscopic and endoscopic excision of the prolapsed disc. Some of these options may not be available in limited resources centers. We will highlight the effectiveness of various surgical options. Twenty patients with foraminal and extraforaminal lumbar disc prolapse were operated upon from January, 2015 to June, 2016 in the neurosurgical departments of Cairo and Fayoum Universities in Egypt by different modalities (open laminectomy with discectomy, microscopic and endoscopic discectomy). Seventeen patients had foraminal disc prolapse and only three patients had extraforaminal disc prolapse. Twelve patients were operated by conventional laminectomy approach. Microscope was used in four patients and four patients were operated endoscopically. Excellent radicular pain improvement was achieved in 15 cases (75\%) including all of the laminectomy groups. Conventional laminectomy and discectomy in far lateral disc prolapse remains an excellent option especially in limited resources centers. Although building up experience with other surgical modalities is mandatory.
\end{abstract}

\section{Keywords}

Far Lateral, Microscopic, Endoscopic, Facetectomy

\section{Introduction}

Back pain is a major public health problem in most industrialized societies. The prevalence rates in several studies ranged from $12 \%$ to $35 \%$ [1], with around $10 \%$ of patients becoming chronically disabled. It also places an enormous economic burden on society. Back pain is strongly associated with degeneration of 
the intervertebral disc [2]. Disc degeneration, although in many cases asymptomatic [3], is also associated with sciatica and disc herniation or prolapse.

Far lateral disc (FLD) herniations account for 6.5\% - 12\% of all lumbar disc herniations. The most affected level is between the fourth and fifth lumbar vertebrae followed by the third and fourth level [4]. Patients with far lateral disc herniations usually present by lower limb radicular pain rather than back pain or both [5].

Conservative management is the first line of treatment. Failure of medical treatment and progressive neurological deficits are the commonest indications for surgical treatment [6].

Operative resection techniques include minimally invasive procedures such as microscopic discectomy and endoscopic discectomy or laminotomy, hemilaminectomy, and laminectomy with or without fusion which may require degrees of facet resection depending on the location and complexity of the FLD herniation [7].

Some invasive techniques like full laminectomy with full facetectomy often require posterolateral fusion with pedicle-screw fixation, although some authors advocate that unilateral full facetectomy rarely affects stability [8] [9] [10].

Alternatively, the extreme lateral approach performs open or endoscopically removes little bone; thus fusion isn't usually needed. The type and extent of decompression and facet resection must be based on an individual patient's pathology, because no single technique is universally appropriate [11].

Despite the presence of microscope and endoscope in our operating rooms, the availability of experienced neurosurgeons to operate with these tools is not commonly available. So we will evaluate the effectiveness of various surgical techniques of FLD prolapse (foraminal \& extraforaminal) in limited resources centers.

\section{Patients and Methods}

The study was prospectively conducted on 20 patients with far lateral (foraminal \& extraforaminal) lumbar disc prolapse operated upon in the period from January 2015 to June 2016 in the Neurosurgery Departments of Cairo and Fayoum Universities. All patients with foraminal and extraforaminal lumbar disc prolapse not responding to medical treatment. We excluded patients with Recurrent lumbar disc prolapse, Patients with lateral recess stenosis and Patients with evident instability. All patients were subjected to thorough history taking and clinical examination. X-Ray lumbosacral spine with dynamic views (to exclude instability) and MRI of the lumbosacral spine were performed for all patients. CT lumbosacral spine was done for selected cases (for diagnosing lateral herniations, which may not be obvious on MRI). All of the patients were operated upon by either: Laminectomy, facetectomy (medial or full) with discectomy, microscopic or endoscopic discectomy (Figure 1).

Full facetectomy was performed by decortication (drilling) of lateral gutter 
and posterolateral fusion by bone fragments of the lamina without hardware fixation. Full neurological examination was performed to all patients to detect improvement or deterioration of the neurological condition. Improvement of back pain and radicular lower limb pain were assessed. Patients were discharged 3 to 5 days hours with follow up after 10 days and one month in outpatient clinic.

Crosby and Insall outcomes rating scale was used for post-operative outcome monitoring of back pain and radicular pain. This grading scale is divided into; excellent, good, fair to poor and worse (Table 1).

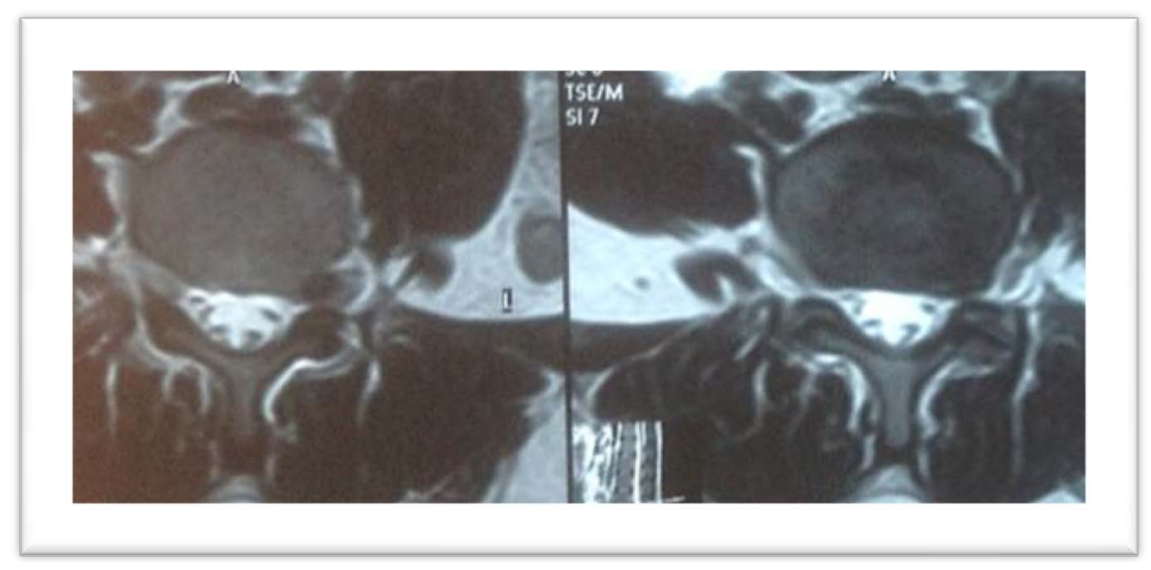

Figure 1. MRI T2 Axial cuts showing L4-5 left extraforaminal disc.

Table 1. Crosby and Insall outcomes rating scale.

\begin{tabular}{cc}
\hline Rating & Outcome \\
\hline Excellent & No pain \\
Normal activity & No limitation in sports participation \\
Full range of motion \\
Knee subjectively normal \\
Occasional discomfort \\
Good \\
Occasional feeling of stiffness or instability \\
No participation in contact sports \\
Slight loss of motion \\
Knee is considered improved from surgery or nearly normal \\
Pair to poor $\quad \begin{array}{c}\text { Pain most of the time } \\
\text { Symptomes have improved by surgery, } \\
\text { but recurrent instability is persistent } \\
\text { Significant loss of motion is present } \\
\text { Instability or dislocation occur more frequently }\end{array}$ \\
\hline
\end{tabular}




\section{Statistical Analysis}

Data were collected and coded to facilitate data manipulation and double entered into Microsoft Access and data analysis was performed using Statistical Package of Social Science (SPSS) software version 18 in windows 7. Simple descriptive analysis in the form of numbers and percentages for qualitative data, and arithmetic means as central tendency measurement, standard deviations as measure of dispersion for quantitative parametric data.

\section{Results}

Among [12] patients of disc prolapse included in the study the mean age was $(43.6 \pm 15.2)$ years old ranged between 21 to 64 years, about gender; $15(75 \%)$ were males and 5 (25\%) were females (Table 2).

Seventeen patients (85\%) were complaining of both back pain and sciatica (foraminal disc prolapse). while three patients (15\%) suffer only from radicular sciatic pains(extra-foraminal).

The sciatic pain was in left lower limb in 12 patients $(60 \%)$ and in the right lower limb in eight patients (40\%).

Mild weakness affecting dorsiflexion of the foot or big toe was among the presenting symptoms in five patients (25\%) while hypoesthesia along dermatomal supply of the compressed root were encountered in nine cases (45\%).

Thirteen patients had their disc prolapse in L4-5 level (65\%) and seven cases (35\%) had L5-1 disc prolapse (Table 3).

Twelve patients $(60 \%)$ were operated upon by open surgical laminectomy, facetectomy (medial or full) and discectomy, 4 patients (20\%) did endoscopic discectomy, and 4 patients (20\%) do microscopic discectomy.

Seventeen patients (85\%) were subjected to only medial facetectomy and only three patients did full facetectomy.

Superficial wound infection was reported in one case (5\%). No other intra or postoperative complications through one month of regular follow up (Table 4).

Post-operative outcome monitoring was scaled by Crosby and Insall outcomes rating scale.

According to Crosby and Insall outcomes rating scale; Excellent improvement of radicular pain was noted in 15 patients (75\%), good improvement was found in 4 patients $(20 \%)$ and no improvement of pain in one $(5 \%)$ of patients. No patients showed any worsening of the pain (Figure 2).

Table 2. Demographic characters of cases.

\begin{tabular}{|c|c|c|}
\hline Variables & & \\
\hline \multicolumn{3}{|l|}{ Age (years) } \\
\hline Mean/SD & 43.6 & 15.2 \\
\hline \multicolumn{3}{|l|}{ Gender } \\
\hline Male & 15 & $75 \%$ \\
\hline Female & 5 & $25 \%$ \\
\hline
\end{tabular}


Table 3. Clinical and radiological characters of cases.

\begin{tabular}{lcc}
\hline \multicolumn{1}{c}{$\begin{array}{c}\text { Variables } \\
(\mathrm{n}=20)\end{array}$} & Clinical characters \\
\cline { 2 - 3 } Clinical presentation & No. & $\%$ \\
$\quad$ Back pain \& sciatica & 17 & $85 \%$ \\
$\quad$ lower limb radicular pain & 3 & $15 \%$ \\
Side of radical pain & & \\
$\quad$ Right side & 8 & $40 \%$ \\
$\quad$ Left side & 12 & $60 \%$ \\
Motor affection & 15 & \\
$\quad$ No & 5 & $75 \%$ \\
$\quad$ weaknesses & & $25 \%$ \\
Sensory affection & 11 & $55 \%$ \\
$\quad$ No & 9 & $45 \%$ \\
$\quad$ Hypoesthesia & & \\
Radiological findings & 17 & $85 \%$ \\
Foraminal disc prolapse & 3 & $15 \%$ \\
Extra-foraminal disc prolapse & & \\
Levels of disc prolapse & 13 & \\
L4-5 disc & & \\
L5-S1 & & \\
\hline
\end{tabular}

Table 4. Operative characters and postoperative complications of cases.

\begin{tabular}{lcc}
\hline & $\begin{array}{c}\text { Variables } \\
(\mathrm{n}=20)\end{array}$ & Clinical characters \\
\cline { 2 - 3 } & & $\%$ \\
\hline Type of procedure & 12 & $60 \%$ \\
Open surgery & 4 & $20 \%$ \\
Endoscopic & 4 & $20 \%$ \\
Microscopic & & \\
Extent of facet resection & 17 & $85 \%$ \\
Medial facetectomy & 3 & $15 \%$ \\
Full facetectomy & & \\
Postoperative complication & 19 & $95 \%$ \\
No & 1 & $5 \%$ \\
Yes & & \\
\hline
\end{tabular}

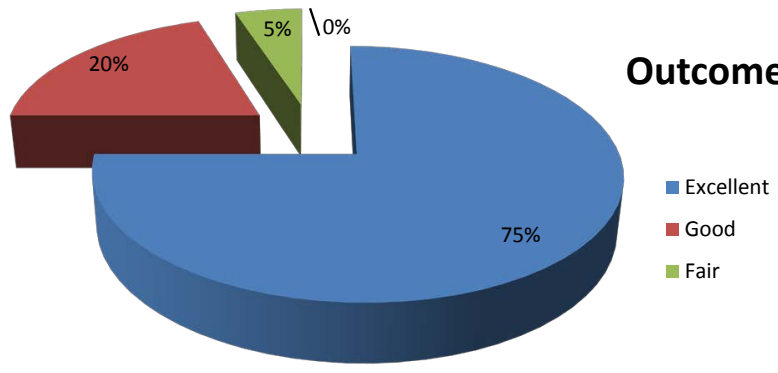

Figure 2. Postoperative outcomes among cases. 


\section{Discussion}

Patients with far lateral disc herniations usually present by lower limb radicular pain rather than back pain or both. Failure of medical treatment and progressive neurological deficit are indications for surgical decompression of the affected nerve root.

Male predominance in our study was nearly like what was found by Samini et al. (10) and Postacchini et al. (12] representing: 75\%, 66.5\% and 62.8\% respectively. A factor may be explained by the increased incidence of men exposure to heavy work and lifting. Most males in our study were farmers, drivers and manual workers.

Lower limb weakness (mainly weak foot dorsiflexion) was present in 5 patients (25\%) of our patients while it represents about 7\% (five patients) of Samini's study group and this higher incidence in our study may be related to delayed seeking of medical advice.

Foraminal disc herniation was present in MRI lumbosacral spine of seventeen patients (85\%) which is comparable to what was reported by Postacchini et al. [13] in their study (79.7\% of their patients with foraminal disc). And the commonest level of far lateral disc is L4-5 (65\% of our patients), similar result was found by Samini et al. [10].

Many surgical options for far lateral disc removal are supported by the literature. Including; open surgical laminectomy with facetectomy then discectomy, microscopic discectomy and endoscopic discectomy.

Full facetectomy or medial facetectomy are familiar corridors known to most surgeons facilitating decompression of emerging nerve root along its course [8] and this is associated with lowest incidence of iatrogenic nerve injury. Although it is not minimally invasive and may be associated with secondary instability post-operative as documented in other studies [9] [14].

Medial facetectomy (removing only $25 \%$ of the facet) is associated with lower incidence of instability and the future need for fusion. [10] [14] [15].

One advantage of open surgical approach is being appropriate especially in limited resources centers where the availability of surgical microscope, endoscope or qualified surgeon not guaranteed.

Medial facetectomy was done in most of our cases (17 patients) and full facetectomy was limited only for the extra foraminal cases and this similar to what was done by Samini et al. [10], Garrido et al. [15] and Epstien et al. [15]. Very limited number of full facetectomy needed future screw fixation in their studies but no patients in our study were fused later.

Stephen et al. mentioned that microscopic approach for far lateral lumbar disc herniations has superiority over open surgical approach as microscope provides good illumination and magnification [16].

Some cases of extra foraminal disc prolapse operated by the microscope may show poor outcome in pain improvement because exposure of the lateral compartment may be limited due to angulation ability of the microscope [17] and this may explain that one of our extra foraminal cases didn't improve and reo- 
perated again.

Sasani et al. [18] mentioned that the use of endoscope in far lateraldisc is superior that open surgery being minimally invasive and variable scopes angles facilitate visualization of the foramen and prolapsed disc. But sometimes in extra foraminal disc, variable degree of facetectomy may be needed but post-operative spondylolisthesis may be reported but with less incidence than open surgical discectomy [19] [20]. In our study, 4 patients were operated upon by endoscopic discectomy with excellent improvement of radicular pain in 2 patients and good improvement in 2 patients.

Intra-operative complications of endoscopic discectomy like nerve root injury (6\%) and early recurrence were reported by Sasani et al. [18] but these complications didn't happen in any of our cases.

Although McCulloch et al. [20] mentioned that endoscopic approach to far lateral lumbar disc herniations is doubtful as most of these herniations are sequestrated segments or uncontained extrusions, but Yeung and Tesow [19] mentioned that usage of a 45 angled endoscope may visualize foraminal extrusions but extraforaminal herniations are still difficult to be visualized endoscopically.

Choi et al. mentioned that endoscopic approach for extraforaminal disc prolapse is a minimal invasive approach with favorable results with soft disc herniations only but if there is any associated pathology like lateral recess stenosis, the open surgical procedures have superiority over endoscopic approach [12].

No intra-operative complications occurred in our patients with one postoperative complication in one patient in form of superficial wound infection managed conservatively with antibiotics and repeated dressing which is like Choi et al. study [12].

Our study limitations include limited numbers and short follow up period which will be considered in future studies.

\section{Conclusion}

Conventional laminectomy and discectomy remains an excellent surgical option in cases of far lateral disc prolapse especially in centers with limited resources where well-trained neurosurgeons on the surgical microscope or endoscope are not commonly available. Meanwhile gaining experience with advanced minimally invasive surgical techniques is mandatory.

\section{Conflicts of Interest}

This study has not been submitted to, nor is under review at, another journal or other publishing venue. The authors have no affiliation with any organization with a direct or indirect financial interest in the subject matter discussed in the study.

\section{References}

[1] Maniadakis, N. and Gray, A. (2000) The Economic Burden of Back Pain in the UK. 
Pain, 84, 95-103. https://doi.org/10.1016/s0304-3959(99)00187-6

[2] Luoma, K., Riihimaki, H., Luukkonen, R., Raininko, R., Viikari-Juntura, E. and Lamminen, A. (2000) Low Back Pain in Relation to Lumbar Disc Degeneration. Spine, 25, 487-492. https://doi.org/10.1097/00007632-200002150-00016

[3] Boden, S.D., Davis, D.O., Dina, T.S., Patronas, N.J. and Wiesel, S.W. (1990) Abnormal Magnetic-Resonance Scans of the Lumbar Spine in Asymptomatic Subjects. A Prospective Investigation. The Journal of Bone \& Joint Surgery, 72, 403-408. https://doi.org/10.2106/00004623-199072030-00013

[4] Doi, T., Harimaya, K., Matsumoto, Y., Tono, O., Tarukado, K. and Iwamoto, Y. (2011) Endoscopic Decompression for Intraforaminal and Extraforaminal Nerve Root Compression. Journal of Orthopaedic Surgery and Research, 26, 6-16. https://doi.org/10.1186/1749-799x-6-16

[5] Hodges, S.D., Humphreys, S.C., Eck, J.C. and Covington, L.A. (1999) The Surgical Treatment of Far Lateral L3-L4 and L4-L5 Disc Herniations: A Modified Technique and Outcomes Analysis of 25 Patients. Spine, 24, 1243-1246. https://doi.org/10.1097/00007632-199906150-00012

[6] Herkowitz, H.N., Rothman, R.H. and Simeone, F.A. (2006) The Spine. 5th Edition, Saunder's ElSevier, Philadelphia, PA, 486-602.

[7] Cervellini, P., De Luca, G.P., Mazzetto, M. and Colombo, F. (2005) Micro-Endoscopic-Discectomy (MED) for Far Lateral Disc Herniation in the Lumbar Spine. Technical Note. Advanced Peripheral Nerve Surgery and Minimal Invasive Spinal Surgery, 92, 99-101. https://doi.org/10.1007/3-211-27458-8 21

[8] Epstein, N.E. (2002) Foraminal and Far Lateral Lumbar Disc Herniations: Surgical Alternatives and Outcome Measures. Spinal Cord, 40, 491-500. https://doi.org/10.1038/sj.sc.3101319

[9] Kuroki, H., Goel, V.K. and Hdekamp, S.A. (2004) Contributions of Flexionextension Cyclic Loads to the Lumbar Spinal Segment Stability Following Different Discectomy Procedures. Spine, 29, 39-46. https://doi.org/10.1097/01.brs.0000106683.84600.e5

[10] Samini, F., Bahadorkhan, G., Ehsaei, M.R. and Kheradmand, H. (2008) Intraforaminal and Extra-Foraminal Far Lateral Lumbar Disc Herniation. Medical Journal of the Islamic Republic of Iran, 22, 63-67.

[11] Drake, R.L., Wayne, Y., Adam, W. and Mitchell, M. (2005) Anatomy of the Back. In: Schmitt, B., Ed., Gray's Anatomy for Students, Elsevier Inc., Chrucill Livingstone, 14-99.

[12] Choi, G., Lee, S.H., Pai, P.R., Lee, S. and Chae, Y.S. (2006) Percutaneous Endoscopic Interlaminar Discectomy for Intracanalicular Disc Herniations at L5-S1 Using a Rigid Working Channel Endoscope. Operative Neurosurgery, 58, 59-68. https://doi.org/10.1227/01.neu.0000192713.95921.4a

[13] Postacchini, F. and Montanaro, A. (1979) Extreme Lateral Herniations of Lumbar Disks. Clinical Orthopaedics and Related Research, 138, 222-227.

[14] Garrido, E. and Connaughton, P.N. (1991) Unilateral Facetectomy Approach for Lateral Lumbar Disc Herniation. Journal of Neurosurgery, 74, 754-756. https://doi.org/10.3171/jns.1991.74.5.0754

[15] Epstein, N.E. (1995) Evaluation of Varied Surgical Approaches Used in the Management of 170 Far-Lateral Lumbar Disc Herniations: Indications and Results. Journal of Neurosurgery, 83, 648-656. https://doi.org/10.3171/jns.1995.83.4.0648

[16] Stephen, M., Sanjai, D., Praveen, V. and Adam, S. (2008) Minimally Invasive Ap- 
proach to Extraforaminal Disc Herniations at the Lumbosacral Junction Using an Operating Microscope: Case Series and Review of the Literature. Neurosurgical Focus, 25, E10. https://doi.org/10.3171/foc/2008/25/8/e10

[17] Kogias, E., Vougioukas, V., Hubbe, U. and Halatsch, M. (2007) Minimally Invasive Approach for the Treatment of Lateral Lumbar Disc Herniations. Technique and Results. Minimally Invasive Neurosurgery, 50, 160-162.

https://doi.org/10.1055/s-2007-985143

[18] Sasani, M., Ozer, A.F., Oktenoglu, T., Canbulat, N. and Sarioglu, A.C. (2007) Percutaneous Endoscopic Discectomy for Far Lateral Lumbar Disc Herniations: Prospective Study and Outcome of 66 Patients. Minimally Invasive Neurosurgery, 50, 91-97. https://doi.org/10.1055/s-2007-984383

[19] Yeung, A.T. and Tsou, P.M. (2002) Posterolateral Endoscopic Excision for Lumbar Disc Herniation: Surgical Technique, Outcome, and Complications in 307 Consecutive Cases. Spine, 27, 722-731. https://doi.org/10.1097/00007632-200204010-00009

[20] McCulloch, J.A. and Young, P.H. (1998) Microsurgery for Lumbar Disc Herniation. In: Essentials of Spinal Microsurgery, Lippincott-Raven, Philadelphia, 329-382. 